\title{
Design and Blade Number Ratio Analysis of Organic Rankine Cycle Radial-Inflow Turbine on Vehicle
}

\author{
Xinyu Li, Zhongxian Han, Peng Li, Lei Wang \\ School of Mechanical Engineering, Tiangong University, Tianjin, China \\ Email: tguhane201@163.com
}

How to cite this paper: Li, X.Y., Han, Z.X., Li, P. and Wang, L. (2021) Design and Blade Number Ratio Analysis of Organic Rankine Cycle Radial-Inflow Turbine on Vehicle. World Journal of Engineering and Technology, 9, 1-14.

https://doi.org/10.4236/wjet.2021.91001

Received: November 6, 2020

Accepted: December 1, 2020

Published: December 4, 2020

Copyright $\odot 2021$ by author(s) and Scientific Research Publishing Inc. This work is licensed under the Creative Commons Attribution International License (CC BY 4.0).

http://creativecommons.org/licenses/by/4.0/

\begin{abstract}
The organic Rankine cycle is widely used in industrial waste heat, engine waste heat and other waste heat recovery applications, and as a key component of the system, it affects the efficiency and output power of the system. In this paper, a centripetal turbine is designed for the organic Rankine cycle, using vehicle exhaust gas as the heat source. Numerical simulations are performed to analyze the effect of the ratio of the number of guide vane blades to the number of impeller blades (vane number ratio) on the turbine performance and flow field. The results show that the effect of the number of impeller blades on the turbine entropy efficiency, the average exit velocity and the temperature of the guiding grate becomes less and less as the ratio of the number of blades increases. The optimum turbine performance is obtained when the number of impeller blades and the ratio of the number of blades are 17 and 1.5882, respectively, and the expansion performance of the guide impeller is improved and the isentropic efficiency of the turbine is improved by $3.84 \%$ compared with the preliminary number of blades.
\end{abstract}

\section{Keywords}

Organic Rankine Cycle, Radial-Inflow Turbine, Blade Number Ratio

\section{Preface}

With the development of society and economy, the energy supply situation in China has become more and more severe [1]. As one of the industries with the largest consumption of petroleum energy, it is particularly important to improve the energy utilization rate of the automobile industry. In the engine of the residual heat, the exhaust energy accounted for about one-third of the total fuel 
energy [2], therefore, the engine of the exhaust waste heat utilization technology has a huge potential for energy saving and emission reduction, improve fuel utilization. The organic Rankine cycle is one of the most effective ways to recover the exhaust waste heat of the engine [3] [4]. As the core component of the organic Rankine cycle that affects the work done, the performance of the turbine expander directly affects the performance of the entire system. Therefore, it is important to design and optimize the turbine expander for the exhaust waste heat of the engine to improve the system performance.

Yue Song [5] designed a centripetal turbine for a medium-high temperature solar heat source and performed numerical simulations to verify the accuracy of the simulations by comparing the agreement between the simulated and designed values. Pei [6] designed a $3.3 \mathrm{~kW}$ radial turbine expander with $71 \%$ and $65 \%$ efficiency in simulations and experiments, respectively. Liu Pan [7] focused on the effect of lobe head clearance on centripetal turbulence. Numerical simulation and aerodynamic performance analysis of the turbine with different lobe top clearances were carried out by CFX, and the results showed that the lobe top clearance influenced the aerodynamic characteristics of the flow field. The results show that the lobe head clearance affects the aerodynamic characteristics of the flow field, and the temperature is the main cause of the deformation of the blades and disk during the turbine operation. Li Yan [8] optimized the structure of the centripetal turbine nozzle and impeller. The results showed that the overall performance was improved after optimization. It provides new ideas for the optimization method of centripetal turbine. Song Liming [9] proposed an automatic design parameterization method for the impeller based on the energy method, and carried out the aerodynamic optimization design for the small spreading chord ratio after loading impeller, and verified the correctness and practicality of the method.

The current research on centripetal turbines mainly focuses on the structure and variable operating performance of the guide impeller and the impeller, but there is a lack of research on the relationship between the number of impeller and impeller blades and their coupling. Therefore, in this paper, we design a centripetal turbine suitable for on-board organic Rankine cycle. The numerical simulation is used to analyze the effect of the number of blades on the performance of the turbine, and the performance and flow field are compared with that of a centripetal turbine with a preliminary number of blades.

\section{Determination of System Working Principle and Turbine Design Condition}

\subsection{Organic Rankine Cycle Systems}

The system structure of organic Rankine cycle is shown in Figure 1, generally consisting of evaporator, condenser, pump and turbine expander four parts. Its workflow is: the engine high temperature exhausts in the evaporator and circulating workpiece heat exchange, so that the circulation of workpiece into high 


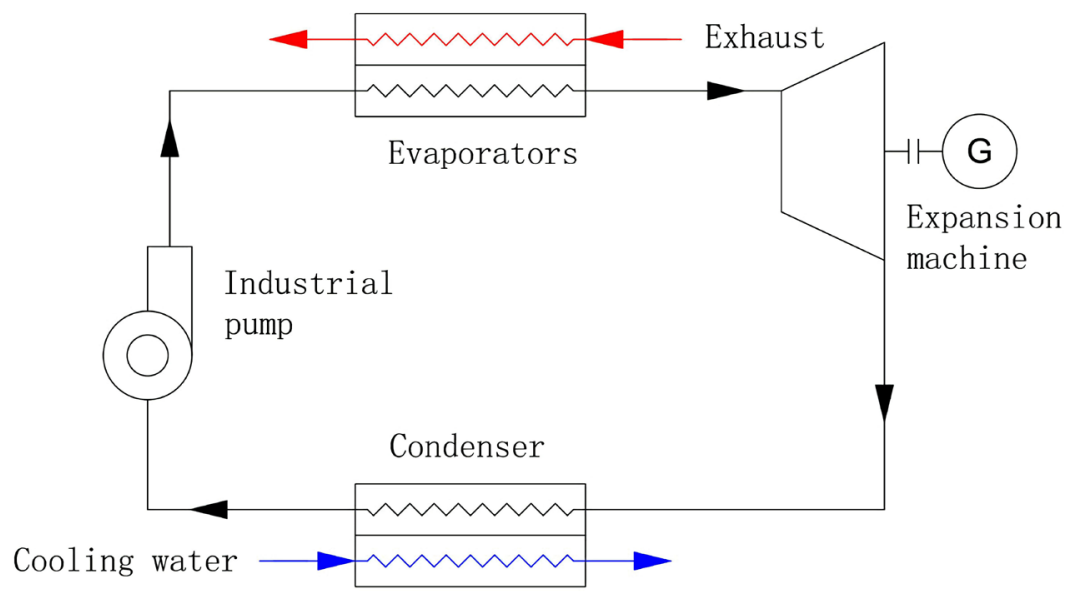

Figure 1. Organic Rankine cycle structure diagram.

pressure and high temperature steam turbine expander work, heat energy into mechanical energy, low temperature and low pressure steam work into the condenser after cooling into the workpiece pump pressurization, into the next cycle.

\subsection{Determination of the Centripetal Turbine Design Condition}

The exhaust gas of a six-cylinder inline heavy-duty diesel engine is selected as the heat source, and the main technical parameters under the set conditions are: exhaust gas outlet temperature of $573 \mathrm{~K}$, displacement of $13 \mathrm{~L}$, maximum torque of $2500 \mathrm{~N}$-m, exhaust gas mass flow rate of $0.75 \mathrm{~kg} \cdot \mathrm{s}^{-1}$. The outlet temperature of the heat exchanger is set at $373 \mathrm{~K}$, assuming that the system is running in a steady state, ignoring the pipeline pressure drop and heat loss [10]. The main components of the exhaust are shown in Table 1.

The thermophysical parameters of the exhaust gas are calculated using the thermophysical calculation software REFPROP according to the composition of the exhaust gas and the thermodynamic model of the organic Rankine cycle. The design parameters for the centripetal turbine are calculated as shown in Table 2.

\section{Pneumatic Design of the Centripetal Turbine}

The thermal and pneumatic design of the centripetal turbine is carried out by MATLAB according to the determined design conditions, and the relative speed ratio, punch angle, expansion ratio and Mach number of guide vane outlet are set according to the known conditions, and the range of the pneumatic parameters are obtained. Taking the circumferential efficiency as an index, a screening method is used to determine the values of backlash, wheel diameter ratio, speed ratio, and airflow angle at the inlet and outlet of the impeller. Finally, the main technical parameters of the centripetal turbine are calculated and corrected as shown in Table 3.

According to the calculated dimensional parameters of the centripetal turbine impeller and the guide impeller, the selected coordinates of the TC series pneumatic impeller of MPEI were imported into UG software to generate the pattern 
Table 1. Main components of diesel engine exhaust.

\begin{tabular}{ccc}
\hline Composition & Molecular mass & Percentage of total \\
\hline $\mathrm{O}_{2}$ & 32.00 & 0.148 \\
$\mathrm{CO}_{2}$ & 44.00 & 0.044 \\
$\mathrm{H}_{2} \mathrm{O}$ & 18.01 & 0.062 \\
$\mathrm{~N}_{2}$ & 28.01 & 0.746 \\
\hline
\end{tabular}

Table 2. Design parameters.

\begin{tabular}{cc}
\hline Parameters & Numerical \\
\hline Turbine inlet pressure & $1.1047 \mathrm{MPa}$ \\
Turbine inlet temperature & $390 \mathrm{~K}$ \\
Turbine export pressure & $0.2610 \mathrm{MPa}$ \\
Turbine inlet mass flow & $1.1425 \mathrm{~kg} / \mathrm{s}$ \\
\hline
\end{tabular}

Table 3. The main design parameters of the turbine.

\begin{tabular}{cc}
\hline Parameters & Numerical \\
\hline Reactionary & 0.52 \\
Wheel diameter ratio & 0.46 \\
Speed ratio & 0.63 \\
Rated speed & $30,000 \mathrm{r} / \mathrm{min}$ \\
Isentropic expansion work & $24.725 \mathrm{~kJ} / \mathrm{kg}$ \\
Outlet diameter of impeller & $55.994 \mathrm{~mm}$ \\
Impeller outlet inner diameter & $20.22 \mathrm{~mm}$ \\
Pilot Blade Outlet Diameter & $99.89 \mathrm{~mm}$ \\
Number of impeller blades & 15 \\
Number of guide leaf blades & 23 \\
Impeller inlet blade height & $3.49 \mathrm{~mm}$ \\
\hline
\end{tabular}

curves and model the guide impeller. ANSYS-BladeGen software was used to enter the dimensional parameters of the impeller in the thickness/angle mode, and the impeller was modeled by radial spatial stacking of different leaf height cross-sections. The completed three-dimensional models of the guide vane and impeller are shown in Figure 2 and Figure 3. Import the coordinates of the guiding impeller runner and impeller model into TurboGrid and divide the structured mesh. The inlet boundary conditions are total pressure and total temperature inlet, the outlet boundary conditions are static pressure, the heat transfer model is Total Energy model, and the turbulence model is $k-\varepsilon$ model.

\section{Calculations and Analysis}

\subsection{Comparison of Design Calculation Results with Simulation Results}

Table 4 shows the CFD numerical simulation results and errors. The errors 


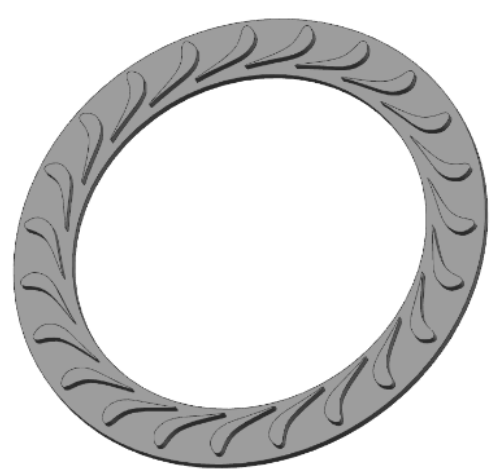

Figure 2. Three-dimensional modeling diagram of guide leaf grille.

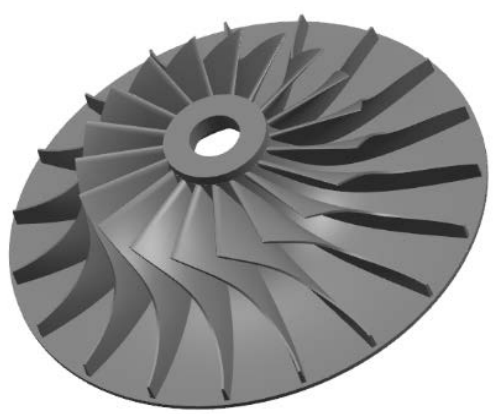

Figure 3. Impeller three-dimensional modeling diagram.

Table 4. Design value and simulation value.

\begin{tabular}{ccc}
\hline Parameters & Analog value & Relative error \\
\hline Turbine inlet pressure & $1.09 \mathrm{MPa}$ & $-1.38 \%$ \\
Turbine inlet temperature & $389.36 \mathrm{~K}$ & $-0.16 \%$ \\
Turbine export pressure & $0.2604 \mathrm{MPa}$ & $-0.23 \%$ \\
Turbine inlet mass flow & $1.16 \mathrm{~kg} / \mathrm{s}$ & $1.51 \%$ \\
Mach number of guide leaf exports & 1.0988 & $2.81 \%$ \\
Average speed of leaf guide exports & $144.281 \mathrm{~m} / \mathrm{s}$ & $-2.21 \%$ \\
Circumferential efficiency & 81.6 & $2.11 \%$ \\
\hline
\end{tabular}

between the design and simulation values in the table are small and less than $3 \%$, and the maximum error in the Mach number of the guide vane exit is $2.81 \%$ due to the supersonic flow of the guide vane gate exit. Overall, the simulation results agree well with the one-dimensional design values, and the design results basically meet the design requirements [5].

Figure 4 shows the change of pressure along the flow line, in which the change of pressure is small before the throat position of the guide impeller, and after the throat position, the change of pressure is large and drops to $0.58 \mathrm{MPa}$. The pressure in the impeller drops uniformly without any obvious jumps and fluctuations, which shows that the shape of the guide impeller and the impeller meets the design requirements. 


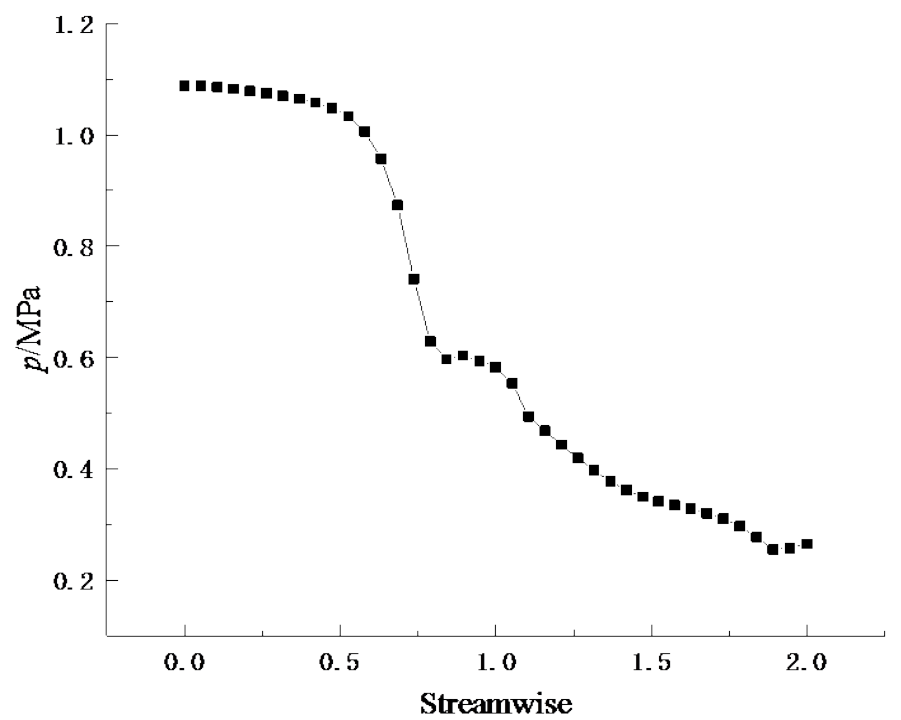

Figure 4. Variation of turbulence pressure along the flow line at the initial number of blades.

\subsection{Effect of Blade Number Ratio on Centripetal Turbulence Performance}

According to Glassman's empirical formula [11], the number of impeller blades can be calculated from Equation (1).

$$
\begin{gathered}
Z_{1}=\frac{\pi}{30}\left(110-\alpha_{1}^{\prime}\right) \tan \alpha_{1}^{\prime} . \\
K_{Z}=\frac{Z_{N}}{Z_{1}} .
\end{gathered}
$$

In the formula, $\alpha_{1}^{\prime}$ is the residual angle of impeller inlet airflow, $Z_{N}$ is the number of blades of the guide impeller, and $Z_{1}$ is the ratio of the number of blades. The number of impeller blades is calculated as $Z_{1}=14.2803$. When the conditions allow, it should be ensured that there is no convention between $Z Z$ and $Z Z$, and it is better to use prime numbers, followed by odd numbers [10]. Therefore, the effect of the number of blades ratio on the turbulence performance is investigated when the number of impeller blades is 13,15, 17, 19 and 21 , respectively.

The main function of the guide louvers is to convert the energy of the materials into kinetic energy with high efficiency, and the lower the outlet temperature and higher the speed of the guide louvers, the better the performance of the guide louvers. Figure 5 and Figure 6 show the effect of the ratio of the number of blades on the average speed and temperature at the outlet of the guide louvers, respectively. The average exit speed of the guide louvers shows an increasing trend with the change of the number of blades ratio, and the change amplitude decreases gradually, while the average temperature of the exit of the guide louvers is just the opposite with the change of the blade ratio. This is due to the increase in the number of blade ratio leads to an increase in the number of blades of the guide louvers, which increases the uniformity of airflow in the guide louvers 


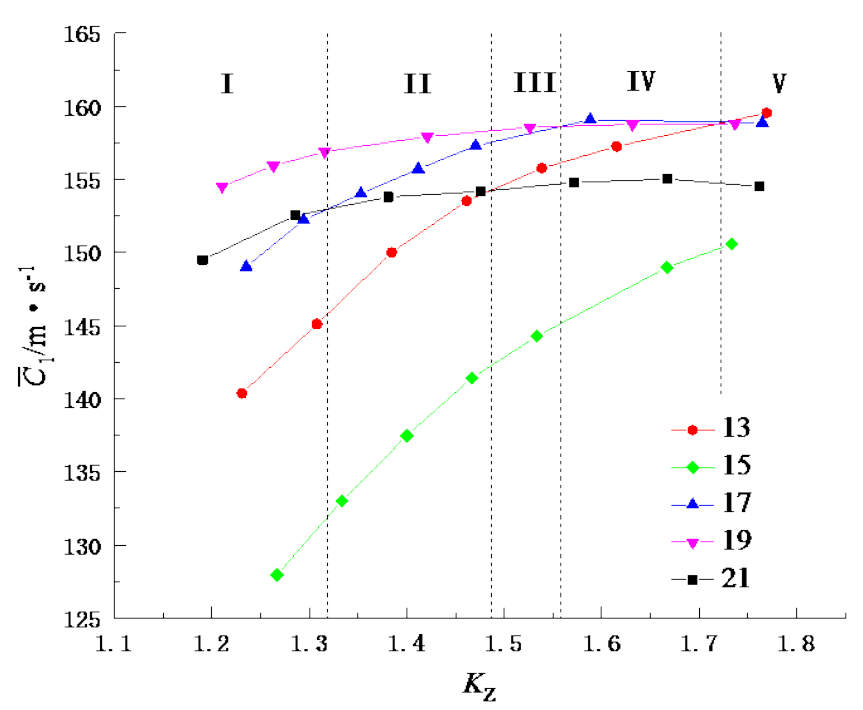

Figure 5. Variation of the average exit velocity of the guided leaf grid as a function of the number of blades ratio.

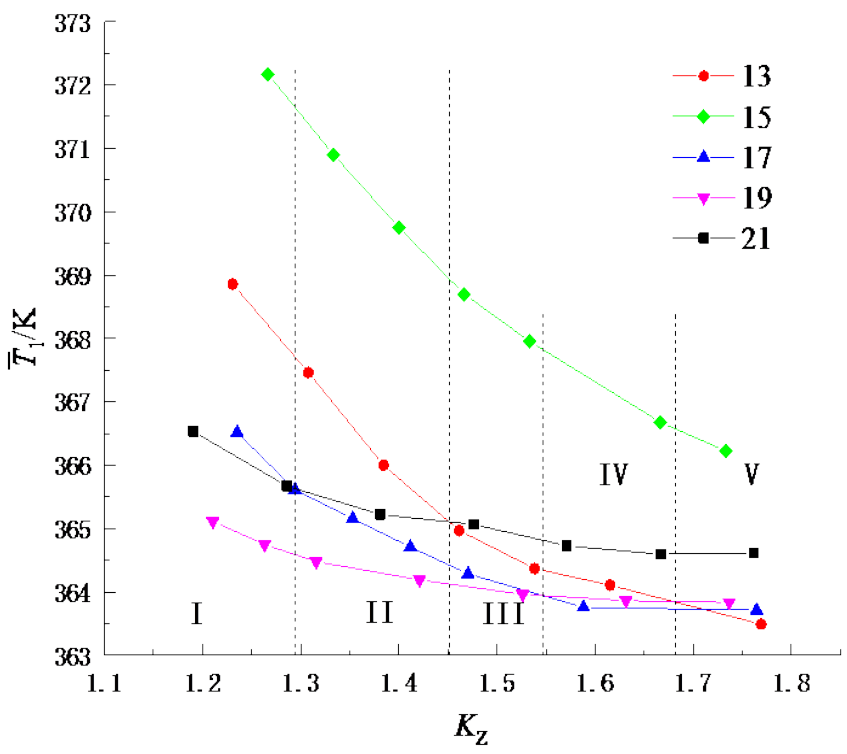

Figure 6. Variation of the average temperature at the outlet of the guide leaf grid as a function of leaf number ratio.

and reduces the generation of swirls; at the same time, the increase in the number of blades of the guide louvers increases the frictional losses in the guide louvers. As a result, the change in the average velocity at the outlet of the guide louvers slows down or even decreases as the number of blades increases.

The number of blade ratios and the number of impeller blades jointly affect the average exit velocity of the guide impeller, and Figure 5 is divided into five regions by the number of blade ratios. In regions I, II, III, IV and V, the blade ratios range from $1.19-1.32,1.32-1.49,1.49-1.56,1.56-1.72$ and $1.72-1.77$, respectively. There is a difference in the priority of the numbers. The ranking in region I is: $19>21>17>13>15$; region II is: $19>17>21>13>15$, region III 
is: $19>17>13>21>15$, region IV is: $17>19>13>21>15$, region V is: $13>$ $19>21>17>15$ The pattern and order of the effect of the number of impeller and the number of blade ratios on the average exit temperature of the guide leaf grid in Figure 6 is exactly opposite to that in Figure 5, with the ranges of the blade ratios in regions I, II, III, IV and V being 1.19 - 1.29, 1.29 - 1.45, 1.45 $1.55,1.56-1.68$ and $1.68-1.77$, respectively.

Figure 7 shows the effect of the blade number ratio on the output power of the centripetal turbine. Due to the increase of the number of blades than the increase of the guide blade in the flow loss, resulting in the output power of the centripetal turbine are showing a downward trend, in order to the number of impeller blades 19 as an example, the blade ratio by 1.21 growth to 1.737 its output power by $31.2 \mathrm{~kW}$ reduced to $22.29 \mathrm{~kW}$, indicating that the number of blades than to the turbine output power of the larger influence.

Figure 8 shows the effect of blade number ratio on the isentropic efficiency of

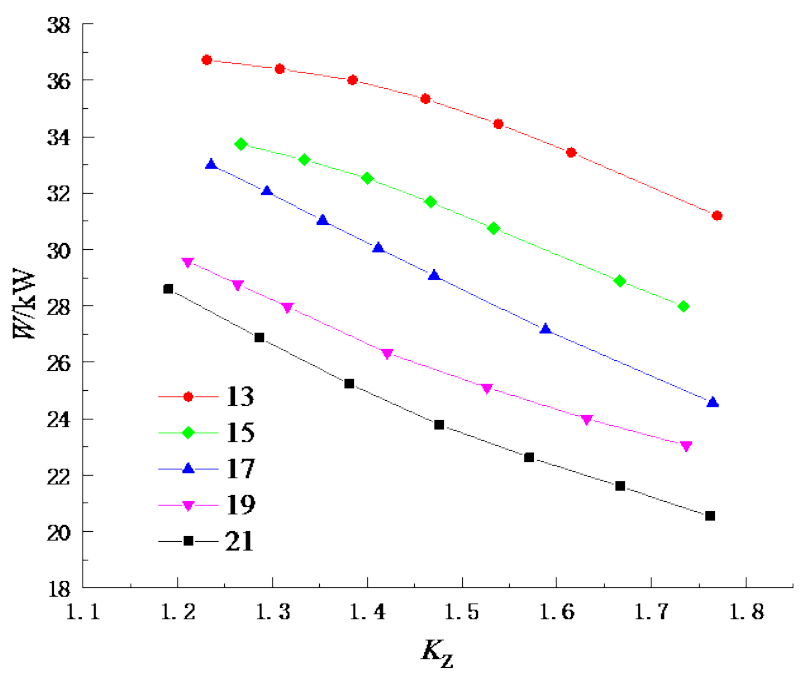

Figure 7. Turbine output power changes with blade number ratio.

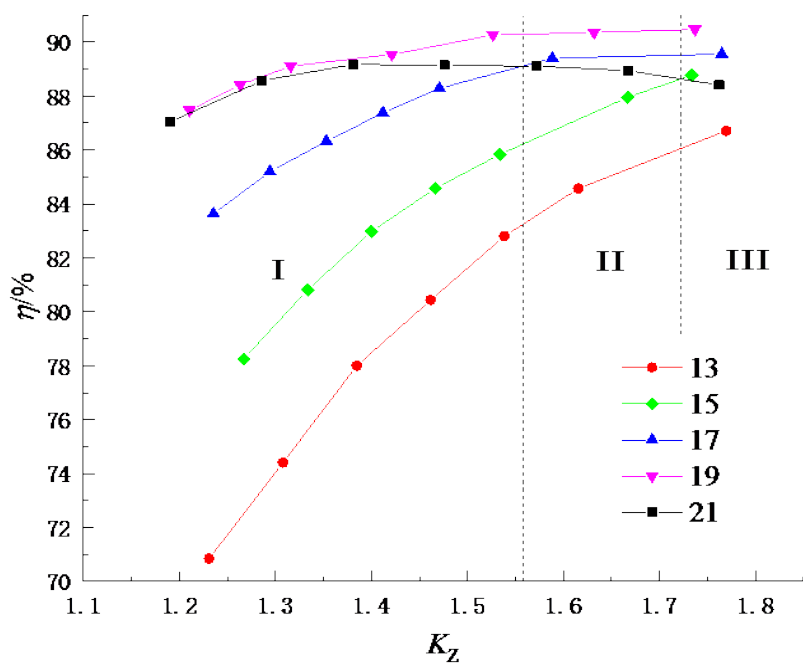

Figure 8. Transparency entropy efficiency changes with blade number ratio. 
centripetal permeability. In the I region where the blade number ratio is 1.19 to 1.558 , except the impeller blade number is 21 , its isentropic efficiency is elevated with the change of blade ratio, when the impeller blade number is 21 , its change trend is first elevated and then lowered and its peak is $89.1739 \%$, the priority order of the impeller blade number in the I region is: $19>21>17>15>13$; in the I region where the blade number is 1.588 to 1.558 , its isentropic efficiency is elevated with the change of blade ratio. In the II region with the blade ratio of 1.72, when the blade ratio is 21 , the isentropic efficiency shows a downward trend with the change of the blade ratio, and the rest shows an upward trend, and the priority ranking of the number of impeller blades in the II region is: $19>17>$ $21>15>13$; in the III region with the blade ratio of 1.72 to 1.77 , the trend of the isentropic efficiency with the change of the blade ratio is consistent with the II region, and the priority ranking of the number of impeller blades in the II region is: $19>17>21>15>13$. The priority order is $19>17>15>21>13$.

In general, the blade number ratio in $1.19-1.588$ region, the impeller blade number for 19 is the more ideal choice; And blade number ratio in 1.588 - 1.77 region, the impeller blade number for 17, 19 has better turbine performance. Consider the turbine performance and blade installation difficulty and other factors, this paper selects the impeller blade number is 17 , blade number ratio is 1.5882 for the best blade number selection.

\subsection{Influence of the Height of the Guide Vanes on the Mass Flow Rate}

The blade height and blade exit angle of the guide cascade have a significant effect on the flow rate of the centripetal turbine [12]. In order to reduce errors and make the mass flow more consistent with the design conditions, the influence of the blade height of the guide cascade on the mass flow and isentropic efficiency of the centripetal turbine is analyzed, and the blade height of the guide cascade is determined.

Figure 9 shows the effect of the blade height of the guide cascade on the entropy efficiency and mass flow of the centripetal transparency. With the change of the blade height of the guide cascade, the mass flow rate shows a linear change trend, and the isentropic efficiency of the turbine shows an upward trend with the blade height, and its change range gradually decreases. According to the design working condition mass flow value of $1.1425 \mathrm{~kg} / \mathrm{s}$, the blade height of the guide vane is determined to be $2.7679 \mathrm{~mm}$.

\subsection{Comparative Analysis of Turbulence Performance at the Initial Number of Blades versus the Optimal Number of Blades}

Table 5 shows the numerical simulation results for the initial number of blades versus the optimal number of blades. Compared with the initial number of blades, the exit temperature of the guide luffing is reduced by $4.012 \mathrm{~K}$ and the exit velocity is increased by $14.352 \mathrm{~m} / \mathrm{s}$, which improves the performance of the 


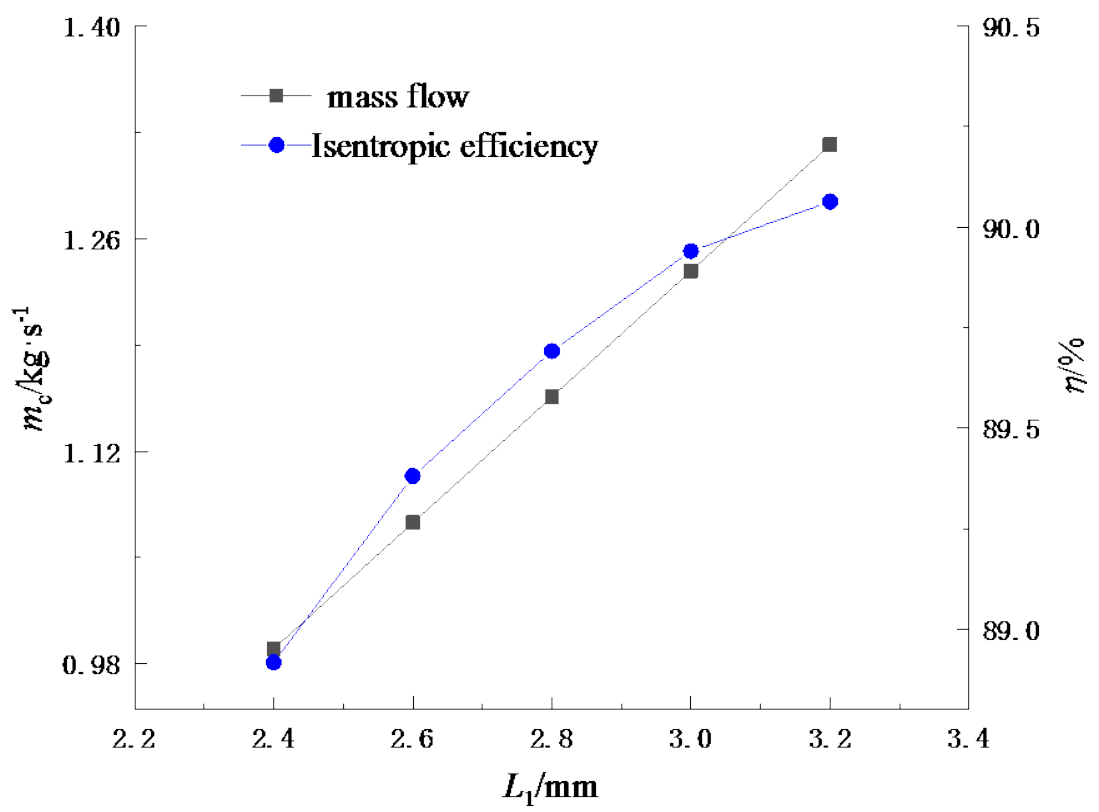

Figure 9. The change of isentropic efficiency and mass flow rate with the height of the guide vane.

Table 5. Preliminary setting of the number of blades and comparison of the values under the optimal number.

\begin{tabular}{ccc}
\hline Parameters & Initial number of blades & Optimal number of blades \\
\hline Turbine inlet pressure & $1.09 \mathrm{MPa}$ & $1.0919 \mathrm{MPa}$ \\
Turbine inlet temperature & $389.36 \mathrm{~K}$ & $389.575 \mathrm{~K}$ \\
Turbine export pressure & $0.2604 \mathrm{MPa}$ & $0.2608 \mathrm{MPa}$ \\
Turbine export temperature & $345.24 \mathrm{~K}$ & $345.494 \mathrm{~K}$ \\
Average speed of leaf guide exports & $144.28 \mathrm{~m} / \mathrm{s}$ & $158.632 \mathrm{~m} / \mathrm{s}$ \\
Turbine inlet mass flow & $1.16 \mathrm{~kg} / \mathrm{s}$ & $1.1426 \mathrm{~kg} / \mathrm{s}$ \\
Pilot Blade Outlet Temperature & $367.956 \mathrm{~K}$ & $363.944 \mathrm{~K}$ \\
Isentropic efficiency & $85.8296 \%$ & $89.67 \%$ \\
\hline
\end{tabular}

guide luffing; the isentropic efficiency of the centripetal turbine is increased by $3.84 \%$, and the simulation results are more consistent with the design conditions.

Figure 10 shows the curve of the pressure versus flow line for the initial number of blades and the optimal number of blades. The trend of pressure in the guide impeller is approximately the same for both the initial and optimum number of blades. The differential pressure in the guiding impeller at optimum blade number increases, and the trend of pressure in the guiding impeller and the impeller is more uniform than before optimization.

Figure 11 and Figure 12 show the flow lines of the guide luff at the initially set number of blades and the optimum number of blades, respectively. Because of the high flow Mach number at the outlet of the guide luff, the excitation intensity 


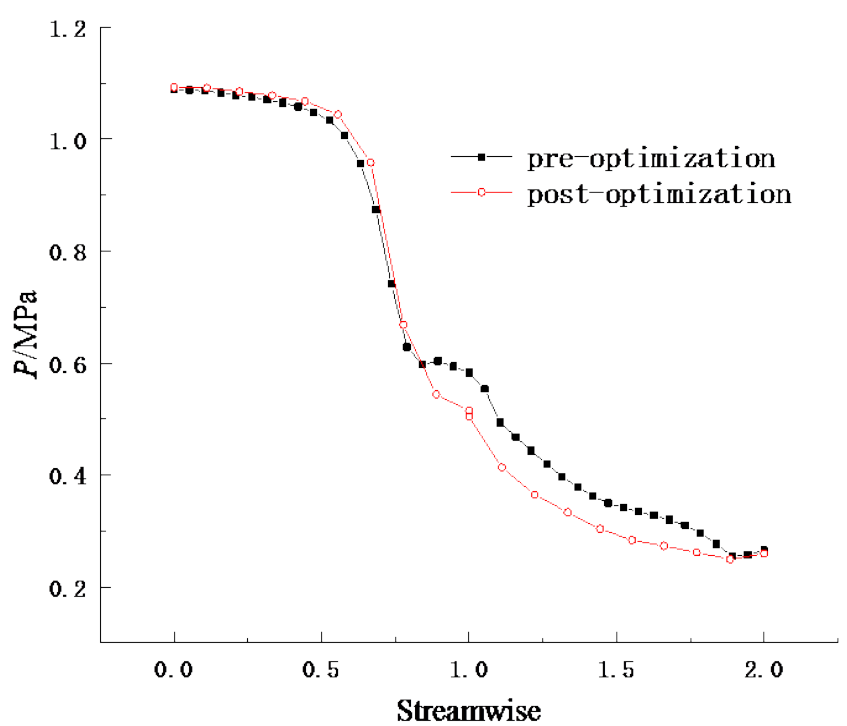

Figure 10. Variation of turbine pressure along the flow line before and after optimization.

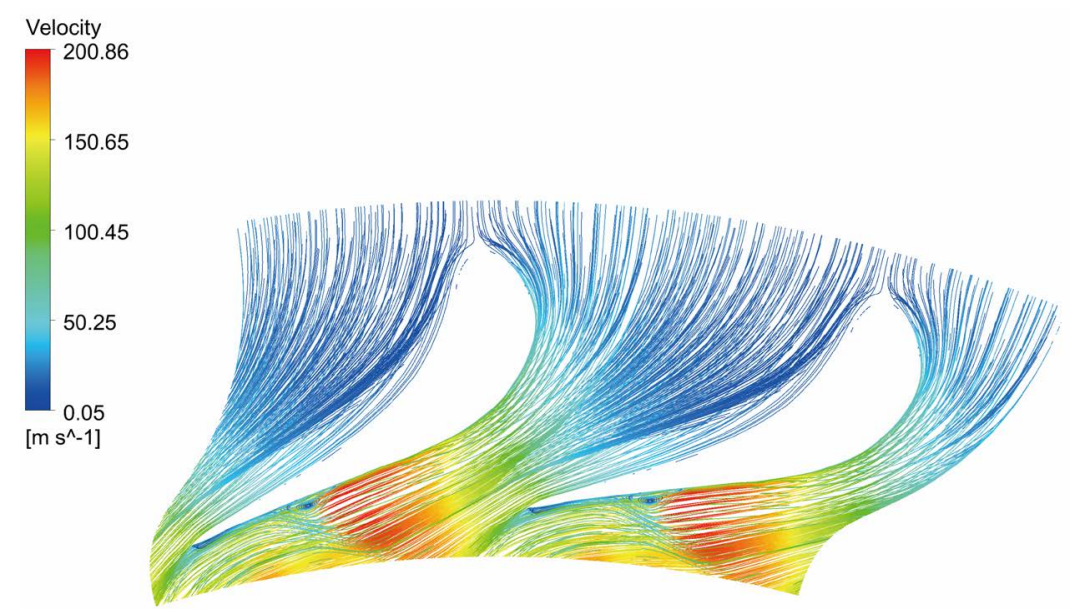

Figure 11. Flowchart of the guide fence at initial number of blades.

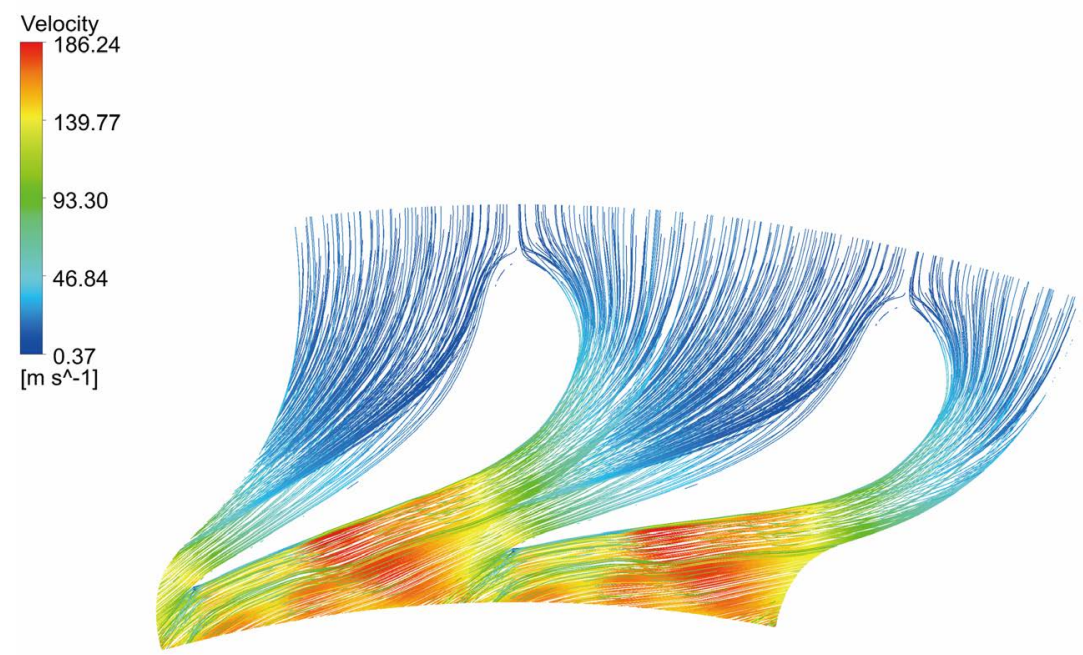

Figure 12. Flow diagram of the guide fence at optimum number of blades. 
is higher, which deflects the flow at the outlet of the guide luff. The deflection of the flow at the outlet of the guide luff is improved at the optimal number of blades, which is due to the increase in the number of blades of the guide luff, which improves the uniformity of the airflow in the guide luff.

Figure 13 and Figure 14 show the clouds and flow lines of the Mach number distribution at $50 \%$ of the leaf height for the initial number of blades and the optimal number of moving leaves. Due to the existence of negative impulse angle at the moving leaf inlet, there is a low Mach region at the pressure surface of the moving leaf inlet for both the initial number of leaves and the optimum number of leaves, which causes airflow separation, which is improved at the optimum number of leaves due to the increase of the number of moving leaves. From the figure, it can be seen that at the optimum number of leaves, due to the back pressure gradient, there is a vortex at the suction surface of the moving leaf, which increases the turbulent flow loss and requires further optimization analysis of the moving leaf shape and the meridional flow path.

\section{Conclusions}

In this paper, the design and numerical simulation of the centripetal turbine were carried out with R123 as the working mass for the engine exhaust heat source. The results show that the relative errors between the simulation results
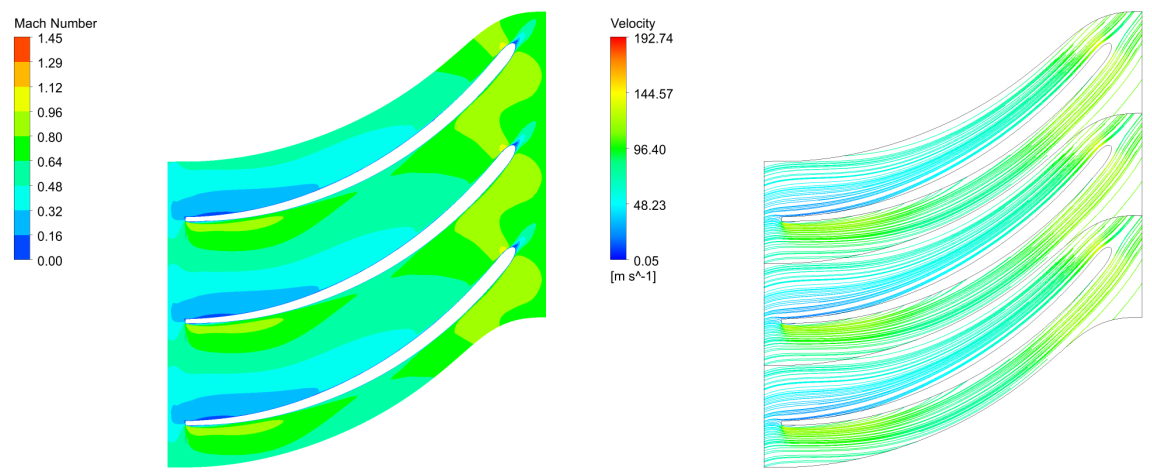

Figure 13. Distribution cloud and streamline diagram of the $50 \%$ leaf height Mach number of the moving blade under the preliminary setting of the number of blades.
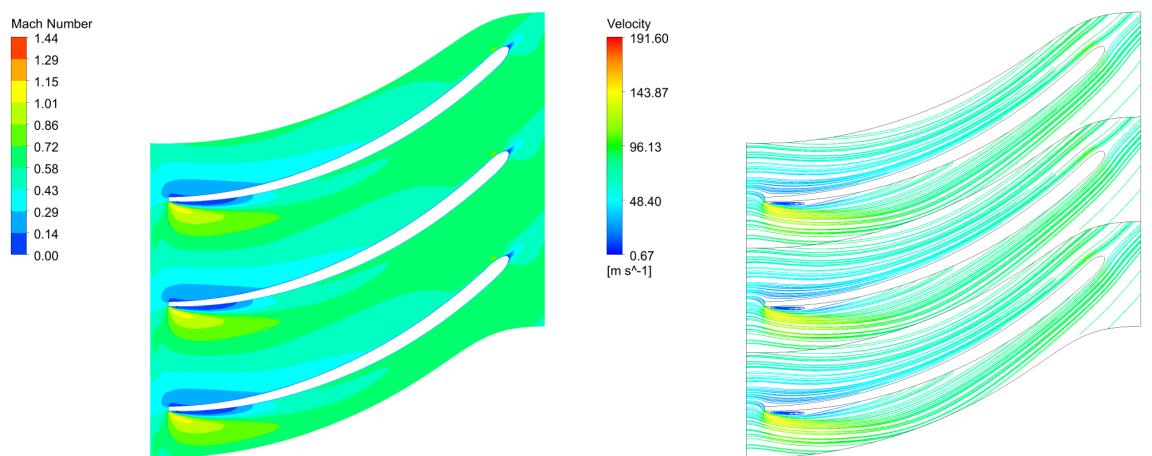

Figure 14. Distribution cloud and streamline diagram of the $50 \%$ leaf height Mach number of the moving blade under the optimal number of blades. 
and the design values are within 3\%, and the pressure changes more uniformly along the flow line, which verifies the accuracy of the turbine design, and analyzes and discusses the ratio of the number of impeller blades to the number of blades, and the conclusions are as follows.

1) As the blade ratio increases, the influence of the number of impeller blades on the turbine entropy efficiency, the average exit velocity of the guide vane and the temperature becomes less and less. In different blade number ratio region, the priority order of impeller blade number is different, this paper considers the turbine performance and the difficulty of blade installation and other factors, and selects the number of impeller blades as 17 and the blade number ratio as 1.5882 as the best choice of blade number. The number of blades and the number of blades ratio selection has certain guiding significance.

2) By comparing the initial number of blades with the optimal number of blades, the performance of the guide louvers was improved at the optimal number of blades, and the isentropic efficiency of the turbine was improved by $3.84 \%$. The pressure change along the flow line was more uniform at the optimum number of blades, and the deflection of the flow line at the outlet of the guide impeller was also improved. The airflow separation at the pressure surface at the impeller inlet was reduced, but the swirl generated at the suction surface increased the flow loss in the impeller, requiring further analysis and research.

\section{Conflicts of Interest}

The authors declare no conflicts of interest regarding the publication of this paper.

\section{References}

[1] Yang, J. (2016) Research on Low Temperature Waste Heat Recovery Technology in Distributed Energy System. Technology and Enterprise, No. 6, 111.

[2] Li, X.N., Shu, G.Q., Tian, H., et al. (2012) An Investigation on Heat Transfer Pinch Point of Engine Exhaust Heat Exchanger. Journal of Engineering Thermophysics, 33, 2058-2062.

[3] Vaja, I. and Gambarotta, A. (2010) Internal Combustion Engine (ICE) Bottoming with Organic Rankine Cycle (ORCs). Energy, 35, 2387-2399. https://doi.org/10.1016/j.energy.2009.06.001

[4] Li, X.Y., Hao, X.T., Meng, L., et al. (2018) Design of Vehicle Organic Rankine Cycle Waste Heat Power Generation System Based on Preheater. Science Technology and Engineering, 18, 230-234.

[5] Yue, S., Zhang, A., Zhang, Y.P., et al. (2015) Aerodynamic Design Study of Radial Inflow Turbine Used in Middle-High Temperature Solar Organic Rankine Cycle System. Journal of Mechanical Engineering, 51, 155-160. https://doi.org/10.3901/JME.2015.04.155

[6] Pei, G., et al. (2011) Construction and Dynamic Test of a Small-Scale Organic Rankine Cycle. Energy, 36, 3215-3223. https://doi.org/10.1016/j.energy.2011.03.010

[7] Liu, P., Wu, Y.D. and Du, C.H. (2015) Investigation on Tip Clearance in a Turbine Based on Fluid-Solid Coupling. Science Technology and Engineering, 15, 84-89+99. 
[8] Li, Y. (2013) Research and Design of the Organic Rankine Cycle and Its Turbine for Low-Temperature Energy Recovery. Master's Thesis, Tsinghua University, Beijing.

[9] Song, L.M., Luo, C. and Feng, Z.P. (2009) Automatic Aerodynamic Optimization Method for Turbine Cascade. Journal of Mechanical Engineering, 45, 109-113.

[10] Wang, H. and Liu, W. (2014) Structure Size and Isentropic Efficiency of Single-Stage Radial Turbine Based on Organic Rankine Cycle. Journal of Tianjin University (Science and Technology), 47, 1088-1094.

[11] Yang, C. (2004) Theory and Design of Radial Flow Turbomachinert. National Defense Industry Press, Beijing.

[12] Li, Y.S. and Lu, G.L. (1987) Radial Inflow Turbine and Centrifugal Compressor. China Machine Press, Beijing. 